\title{
Telomere Length of Multiple Dietary Supplement Users - A Cross-sectional Study in Comparison with Age-matched Controls
}

\author{
Hong Wang*, Bruce Paul Daggy, Jamie Francine McManus, Les G Wong \\ Research \& Development, Shaklee Corporation, Pleasanton, USA \\ Email address: \\ hwang@shaklee.com (H. Wang), bruce.daggy@gmail.com (B. P. Daggy), drjmcmanus@shaklee.com (J. F. McManus), \\ lwong@shaklee.com (L. G Wong) \\ ${ }^{*}$ Corresponding author
}

\section{To cite this article:}

Hong Wang, Bruce Paul Daggy, Jamie Francine McManus, Les G Wong. Telomere Length of Multiple Dietary Supplement Users - A Crosssectional Study in Comparison with Age-matched Controls. Journal of Food and Nutrition Sciences. Vol. 6, No. 5, 2018 , pp. 129-134. doi: $10.11648 /$ j.jfns.20180605.13

Received: October 10, 2018; Accepted: November 2, 2018; Published: November 26, 2018

\begin{abstract}
Telomeres are DNA-protein complexes that cap chromosomal ends to promote chromosomal stability. Telomere length has been associated with diet and nutrition and inversely associated with mortality, life stress, and diseases. The objective of the current study was to explore the effect of long-term intake of multiple dietary supplements on telomere length in adults compared with age-matched controls. Salivary telomere lengths were determined from a group of heavy supplement users (HSU group; $n=81 ; 20$ males and 61 females age 30-79), the majority of whom took $>12$ different supplements daily at least 4 days per week for at least 5 years, compared to a population of relatively healthy, non-smoking, age-matched subjects in the San Francisco Bay Area (control group; n=323; 146 males and 177 females) who took $\leq 3$ different supplements daily. Telomere lengths were measured by quantitative PCR to determine the telomere-to-single copy gene (T/S) ratio and were compared between groups that were age-matched by decade from 30 to 79 . There was an age effect ( $\mathrm{p} \leq 0.05)$ and a significant difference between groups $(\mathrm{p} \leq 0.001)$. The HSU group had significantly longer telomere length in the $50 \mathrm{~s}$, $60 \mathrm{~s}$, and $70 \mathrm{~s}$ age groups ( $\mathrm{p} \leq 0.01,0.001,0.01$ respectively). Routine clinical blood chemistry biomarkers (glucose, lipid profiles, liver enzymes, renal function and CRP) in both groups were all within the normal ranges. The results of this cross-sectional study suggest that heavy dietary supplementation may attenuate telomere shortening compared to an age-matched control group. Longitudinal studies are needed to further explore the potential association between nutritional supplementation, healthy aging and the reduced rate of telomere shortening.
\end{abstract}

Keywords: Telomere Length, Telomere Shortening, Dietary Supplements, Nutrients, Diets, Oxidative Stress, Inflammation

\section{Introduction}

Telomeres are DNA-protein complexes that cap chromosomal ends, keeping these ends from fusing with each other and from being recognized as a double strand break by DNA repair proteins in the cell. During cell division, DNA replication cannot fully copy to the extreme ends of the linear chromosome leading to telomere attrition during cell division. Although telomerase can add telomeric repeat sequences to the end of chromosome, its levels and activity are limited in many human cells leading to the telomere shortening throughout the life span [1]. Telomere length has been associated with lifestyle, diet and nutrition and inversely associated with aging, stress and diseases [2-6]. Short telomeres are also associated with mortality risk [1]. Leukocyte telomere length is correlated with telomere length of various tissues and the systemic influence on telomere maintenance and has been proposed as a surrogate biomarker $[1,7]$ which may reflect physiological age and health status.

Previously a cross-sectional study showed that long-term multiple dietary supplement usage was associated with significantly improved nutritional status and multiple measures of health status [8]. Other clinical studies had shown that multivitamin use in women [9] and 
micronutrients consumption in a Korean middle-aged population [10] were associated with longer telomere length. Increasing blood levels of carotenoids were shown to be associated with longer telomere length in some US populations [11]. Other nutrients such as vitamin $\mathrm{C}$, vitamin $\mathrm{D}$, and omega-3 fatty acids levels were also associated with longer telomeres or attenuation of telomere shortening [1215]. The blood levels of these nutrients are directly related to dietary intake from food or dietary supplements. All these studies suggest a potential impact of dietary supplement use on telomere length. The objective of the current crosssectional study was to explore the effect of long-term multiple dietary supplementation intake on telomere length compared to age-matched controls.

\section{Methods}

\subsection{Participants}

Two groups of participants (male and female, age between 30-79 years old) were recruited. 1) Heavy Supplement Users (HSU) group: supplement users who had been product consumers of a dietary supplement manufacturer and distributor (Shaklee Corporation, Pleasanton, CA) who took at least 5 different supplements 4-7 times weekly for at least 5 years. Participants in HSU group were from all regions of the mainland US. 2) Control (CON) group: relatively healthy non-smokers who took no more than 3 different supplements daily. CON participants were living in San Francisco Bay Area.

\subsection{Recruitment}

1) HSU group: recruited at a conference held by the supplement distributor in Pleasanton, CA.

2) CON group: recruited through agreements with local companies who agreed to advertise the study and allow their employees to participate at the workplace. Recruitment was via email flyers sent by each employer's Human Resource department. Additional residents in the San Francisco Bay area were recruited through newspaper and radio advertisements, fliers and online ads.

\subsection{Inclusion Criteria}

1) HSU group: men and women aged between 30-79 years old residing in mainland USA who used at least 5 different supplements 4-7 times weekly for at least 5 years and were willing to sign the informed consent form. Dietary supplement usage information in this group was assessed via online survey questionnaires completed by $74 \%$ of HSU participants. Common supplements used include single- and multi-vitamins and minerals, fish oil, and supplements with various combinations of herbal extracts. Within the returned responses for supplements taken 4-7 times weekly, $98 \%$ of respondents were taking a multi-vitamin, multi-mineral supplement, $94 \%$ were taking single vitamins or a mixed carotenoid supplement, 55\% were taking mineral supplements, $97 \%$ were taking supplements containing omega-3 fatty acids and 91\% were taking a resveratrol and muscadine polyphenols supplement.

2) CON group: relatively healthy men and women aged between 30-79 years old residing in SF Bay Area who were English-speaking and willing to sign the informed consent form and keep healthy behaviors stable for one year.

\subsection{Exclusion Criteria}

1) HSU group - no exclusion for participation.

2) $\mathrm{CON}$ group - those with health conditions and/or taking medications that would affect telomere length except for those in aged 60-70s years old with mild conditions of aging and common medications (statins or antihypertensives). Anyone who used tobacco or recreational drugs, was obese (BMI $>35 \mathrm{~kg} / \mathrm{m}^{2}$ ), took more than 3 daily supplements, or took $>1 \mathrm{~g} /$ day supplemental omega-3 fatty acids from fish oil was excluded from the CON group.

\subsection{Study Site}

Sample collection and processing as well as telomere length assay and data collection were performed by Telomere Diagnostics, Menlo Park, CA. The study protocol was reviewed and approved by Institutional Review Board (Ethical \& Independent Review Services, Corte Madera, CA). All participants provided informed consent.

\subsection{Telomere Length Test}

Quantitative PCR was used to measure average telomere length per genome (i.e. telomere-to-single copy gene (T/S) ratio) in saliva cellular DNA. Saliva was used because of its ease of collection and storage. Saliva DNA sample was shown to be a viable alternative to blood samples [16] and the main source of the DNA comes from saliva leukocytes [17]. Saliva samples were collected with Oragene DNA collection kit (Ontario, Canada).

\subsection{Blood Chemistry Test}

Fasting blood samples were assayed for routine blood chemistry tests by LabCorp Testing Laboratory (Burlington, NC). Exclusion criteria also included missing, ineligible participants' biological specimens or samples where hemolysis invalidated the reading.

\subsection{Data Collection, Exclusion and Statistics Analysis}

Telomere length was reported as a $\mathrm{T} / \mathrm{S}$ ratio (telomere signal normalized relative to a single copy gene signal). Samples with $\mathrm{T} / \mathrm{S}$ ratio $>2.0$ were excluded from the data set due to potential artifact [18]. Exclusion criteria also included missing or ineligible participants' biological specimens or where hemolysis invalidated the reading. After exclusion, 
there were 323 subjects in the CON group and 81 in the HSU group that were within the age from 30 to 79 years old (Figure 1). T/S ratios of HSU supplement group were compared to those in the age-matched $\mathrm{CON}$ group by using linear regression and two-way ANOVA with multiplecomparisons (Bonferroni post-hoc test) using Graphpad Prizm 6.0. P-values $\leq 0.05$ was considered statistically significant.

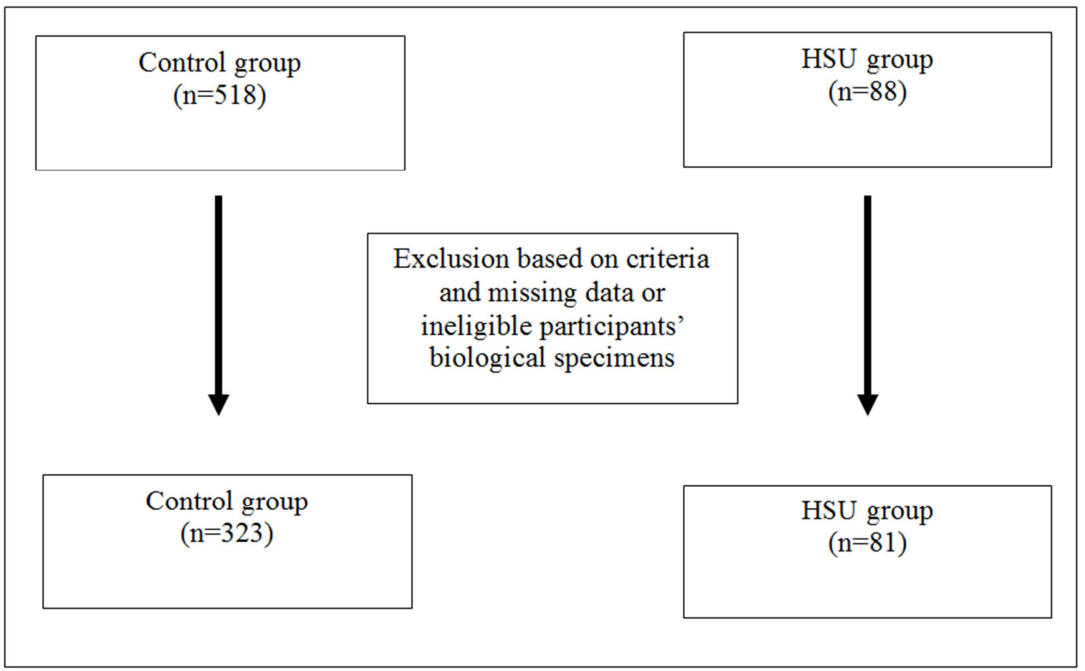

Figure 1. Flow diagram of the numbers of participants from recruitments to data analysis.

\section{Results}

a)

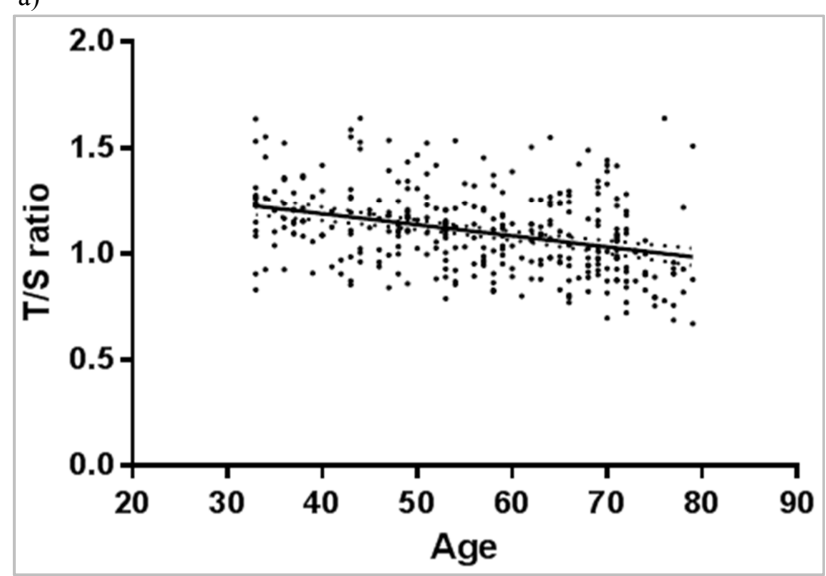

b)

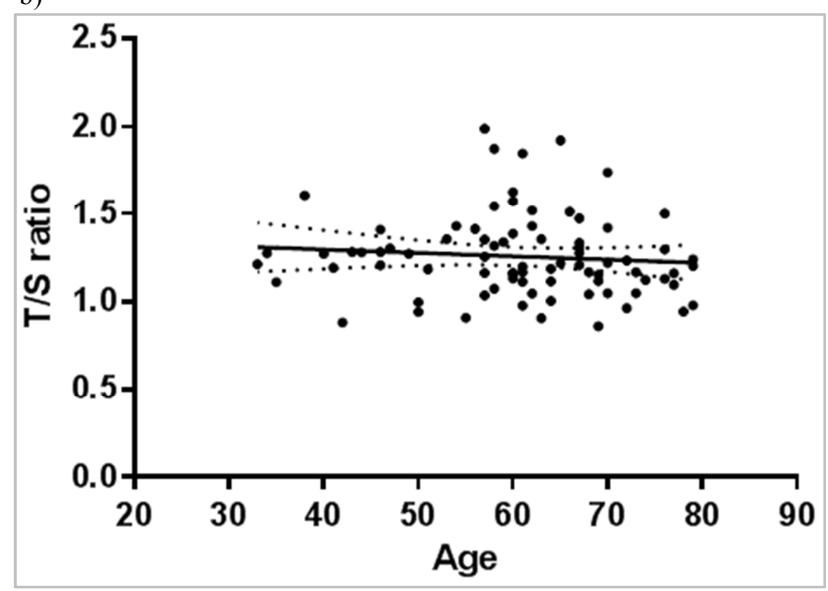

c)

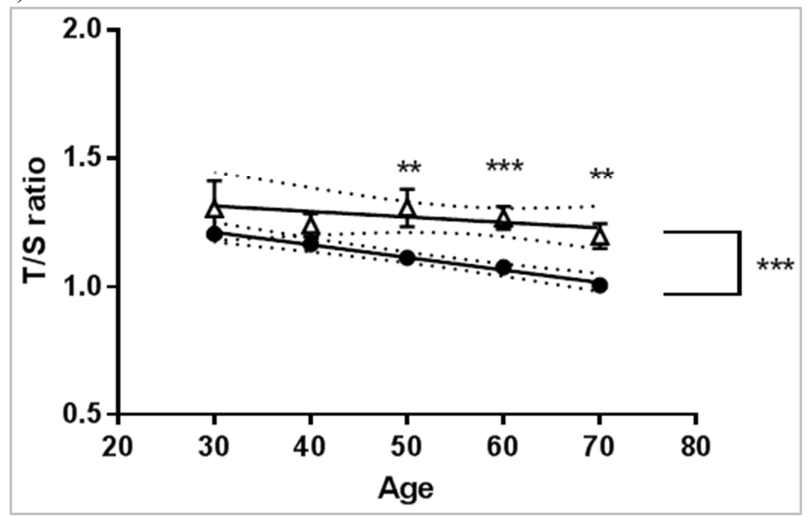

Figure 2. Scatter plot of the participants' salivary telomere length (T/S ratio) a) CON group b) $H S U$ group. Linear regression was used to plot the straight line. c) Age-matched data in decades of from $\mathrm{CON}(\bullet)$ and $\mathrm{HSU}(\Delta)$ group are shown with each dot represented the mean \pm S.E.M. Linear regression was used to plot the line of best fit. Two-way ANOVA with multiple comparisons (Bonferroni post-hoc test) was used to compare the agematched by decade from 30s to 70 s between groups. There was an age effect $(p \leq 0.05)$ and a significant group difference $(p \leq 0.001)$ with no significant interaction $(p=0.5488)$. The HSU group had significantly longer telomere length in the age group at 50s, 60s and 70s. ${ }^{*} p \leq 0.01, * * * p \leq 0.001$.

The results of the salivary telomere length of the participants from 2 groups are shown in Figure 2. Scatter plots of each group are shown in a) and b). Then, the data were grouped based on their age in the decades from $30 \mathrm{~s}$ to $70 \mathrm{~s}$ as shown in c). Linear regression was used to plot the graph for each group (CON: $\mathrm{Y}=-0.004869 * \mathrm{X}+1.357$; HSU: $\mathrm{Y}=-0.002107 * \mathrm{X}+1.375)$. There is no significant difference between the slopes of the lines. When using two-way ANOVA with multiple comparisons for between-group comparisons by decade from 30 s to 70 s, there was an age 
effect $(\mathrm{p} \leq 0.05)$ and a significant difference between groups $(p \leq 0.001)$ with no significant interaction $(p=0.5488)$. The HSU group had significantly longer telomere length in the age group at $50 \mathrm{~s}, 60 \mathrm{~s}$ and $70 \mathrm{~s}(\mathrm{p} \leq 0.01,0.001,0.01$ respectively).

The blood chemistry results from two group of participants are shown in Table 1. All the means were within normal ranges in both groups.

Table 1. Blood chemistry data of participants.

\begin{tabular}{lll}
\hline Blood Chemistry Parameters & CON & HSU \\
\hline Glucose $(\mathrm{mg} / \mathrm{dL})$ & $87.05 \pm 11.35$ & $93.25 \pm 18.6$ \\
BUN $(\mathrm{mg} / \mathrm{dL})$ & $15.62 \pm 4.31$ & $17.35 \pm 3.8$ \\
CRE $(\mathrm{mg} / \mathrm{dL})$ & $0.88 \pm 0.19$ & $0.85 \pm 0.2$ \\
Total Protein $(\mathrm{g} / \mathrm{dL})$ & $6.97 \pm 0.42$ & $7.21 \pm 0.4$ \\
Albumin $(\mathrm{g} / \mathrm{dL})$ & $4.46 \pm 0.29$ & $4.57 \pm 0.3$ \\
Globulin $(\mathrm{g} / \mathrm{dL})$ & $2.55 \pm 0.33$ & $2.64 \pm 0.3$ \\
Total Bilirubin (mg/dL) & $0.55 \pm 0.32$ & $0.43 \pm 0.2$ \\
Alkaline Phosphatase (U/L) & $62.79 \pm 18.05$ & $67.14 \pm 16.7$ \\
LDH (U/L) & $153.53 \pm 27.44$ & $169.72 \pm 25.4$ \\
GGT (U/L) & $23.41 \pm 26.85$ & $23.13 \pm 15.5$ \\
Aspartate Aminotransferase (U/L) & $21.25 \pm 9.81$ & $23.65 \pm 7.4$ \\
Alanine Aminotransferase (U/L) & $21.08 \pm 15.66$ & $22.78 \pm 8.3$ \\
Uric Acid (mg/dL) & $5.21 \pm 1.29$ & $4.95 \pm 1.2$ \\
Triglycerides, Serum & $102.42 \pm 57$ & $94.18 \pm 42.5$ \\
Cholesterol (mg/dL) & $196.19 \pm 37.72$ & $212.7 \pm 41.1$ \\
HDL(mg/dL) & $63.22 \pm 18.61$ & $69.86 \pm 19.6$ \\
LDL (mg/dL) & $112.91 \pm 32.24$ & $124.06 \pm 39.3$ \\
Iron, Total ( $\mu \mathrm{g} / \mathrm{dL})$ & $102.93 \pm 32.77$ & $124.49 \pm 35.6$ \\
CRP (mg/dL) & $1.25 \pm 1.69$ & $2.79 \pm 4.3$ \\
\hline
\end{tabular}

Data are shown in mean \pm S.D. $($ CON $n=296 ;$ HSU $n=81)$

BUN: blood urea nitrogen; CRE: creatinine; LDH: lactate dehydrogenase; GGT: gamma-glutamyl transferase; HDL: high density lipoproteins: LDL: low density lipoproteins; CRP: C-reactive protein.

\section{Discussion}

Telomere length has been shown to associate with aging, diseases, life style, stress, diet and nutrition [2-6]. Telomere length is heritable but can be modified by various environmental factors and health status. Key factors affecting telomere length are oxidative stress, inflammation and DNA integrity [5]. Diet and nutrition including several nutrients or phytonutrients which have been associated with attenuation of telomere shortening can be categorized based on these three factors.

Oxidative stress and inflammation play a significant role in aging and diseases that contribute to tissue injury with cellular and DNA damage. Many antioxidants and antiinflammatory agents can attenuate telomere shortening [19]. Oxidative stress can cause oxidative base modifications and DNA breaks [5]. Oxidative damage is repaired less well in telomeric DNA and oxidative stress accelerates telomere loss, whereas antioxidants decelerate it [20]. Nutrients such as carotenoids, vitamin $\mathrm{C}$ and vitamin $\mathrm{E}$ are well-known antioxidants and play a significant role in the body to protect against oxidative stress. These nutrients have been shown to associate with longer telomere length in three different population group [9-12].

Inflammation increases the rate of immune cell turnover and replication, which would contribute to telomere attrition. In addition, activated immune cells during inflammation generate reactive oxygen and nitrogen species that cause oxidative stress-induced DNA damage [21]. Infectioninduced chronic inflammation in patients was associated with shortened telomere length $[22,23]$ illustrating the significant role of inflammation. Therefore, certain nutrients that can counter inflammation in the body could potentially attenuate its deleterious effects on telomere shortening. In addition to the enhancement of calcium absorption, vitamin D has antiinflammatory actions via multiple pathways. Serum vitamin D levels were negatively associated with C-reactive protein (CRP), an inflammatory biomarker [14] and were positively associated telomere length [14, 24, 25]. Many inflammatory mediators generated in the body originate from cell membrane lipids. Dietary lipids have direct impact on the types and amount of fatty acids incorporated into cell membranes. Omega-6 (n-6) fatty acids such as arachidonic acid are the precursors that generate pro-inflammatory prostaglandins and leukotrienes, in contrast to omega-3 (n-3) fatty acids, including eicosapentaenoic acid (EPA) and docosahexaenoic acid (DHA), which are precursors to many anti-inflammatory prostaglandins and resolvins. There was an inverse association of omega-3 fatty acids levels with the rate of telomere shortening over 5 years in coronary heart disease patients in a longitudinal study [15]. Omega-3 supplementation in healthy overweight middle aged and older adults for 4 months reduced oxidative stress, and the lower $n-6: n-3$ ratio from this supplementation was associated with an increase in telomere length [13]. Other food components that have anti-inflammatory effects based on negative dietary inflammatory index scores can also contribute to effects on telomere length [26, 27].

Telomere length is influenced by DNA integrity and DNA and histone methylation [28]. Folate is essential for the production and maintenance of DNA and cell cycle progression through methylation. However, when there is loss of DNA and histone methylation, epigenetic regulation is lost resulting a more elongated telomere than normal [5]. Therefore, the effects of folate on telomere length depend in part on cellular status. While consumption of folate based on a food frequency questionnaire was positively associated with telomere length in middle-aged Korean adults $<50$ years old and not older [10], leucocyte telomere length and plasma folate status had been studied in a group of Italian men and [29] and a larger study in Framingham Offspring cohort [28]. However, the results from these two studies were not consistent with each other with the Italian men study showing the plasma folate level had a U-shaped relationship with telomere length but was shown inversely associated with telomere length only at very high plasma folate level in the Framingham cohort study. Therefore, the actual relationship between folate status and telomere length remains unclear. 
Besides single nutrients, certain healthy diet patterns or food groups were also associated with telomere length. A recent systemic review supported the findings that adherence to Mediterranean diet (MD) was associated with longer telomere length; fruits and vegetables are the two food groups which showed positive association [30]. The MD is characterized by: a high intake of vegetables, fruits, legumes and grains; a high intake of olive oil and low in saturated fat; a moderately high intake of fish; a low intake of dairy products, meat and poultry; and a regular intake of wine. There are well-established protective effects of the MD on oxidative stress and chronic inflammation which may explain the favorable influence on telomere length [31]. Key phytonutrients from the diet are polyphenols, found in fruits and vegetables, olive oil, coffee and wine. Polyphenol intake from a MD was shown to reduce the inflammation and improve cardiovascular and mortality risk [32-34]. A recent study also showed that higher adherence to a healthy diet using Mediterranean Diet scores, Healthy Eating Index-2010 scores, and Dietary Approaches to Stopping Hypertension (DASH) scores as the diet quality indices were each associated with longer telomere length in women [35].

In the current cross-sectional study, the salivary telomere lengths from age-matched long term heavy supplement users were compared to those of relatively healthy controls, who did not have conditions or behavior such as smoking that may affect the telomere length. The results showed that there are an age effect and a significant difference between groups. The HSU group had longer telomeres than the CON group from age $50 \mathrm{~s}$ to $70 \mathrm{~s}$. Both groups had normal blood chemistry including CRP within the normal range. The results seem to reflect a previous study, which showed that long-term multiple dietary supplement usage was associated with significantly improved health and nutritional status [8]. Within the returned responses of the supplement use questionnaires from the HSU participants for supplements taking 4-7 times weekly, 98\% were taking a multi-vitamin, multi-mineral supplement, 94\% were taking single vitamins or a multi-carotenoid supplement, $55 \%$ were taking mineral supplements, $97 \%$ were taking supplements containing omega-3 fatty acids and 91\% were taking a resveratrol and muscadine polyphenols supplement. Similar to other studies of diet pattern's association with telomere length, it is difficult to pinpoint exact mechanisms or contributions of the individual components' potential effects and interactions in this study, particularly in the absence of measures of nutrient status for these subjects.

\section{Conclusions}

This study showed that long-term multi-supplement users had longer telomere length in their 50s, 60s and $70 \mathrm{~s}$ compared to controls. The results suggest that heavy dietary supplementation may attenuate telomere shortening and is consistent with a previous study's findings that long-term multiple dietary supplement usage was associated with significantly improved health and nutritional status. Based on the published literature and putative mechanisms, supplements containing vitamins $\mathrm{C}, \mathrm{D}$ and $\mathrm{E}$, carotenoids, omega-3 fatty acids and polyphenols may all contribute to the effects on telomere length. Further research, including prospective longitudinal studies, is needed to have a better understanding of the active nutrients and their mechanisms of action.

\section{Conflict of Interest Statement}

The authors declare that they have no competing interests.

\section{Abbreviations}

HSU: heavy supplement users; CON: control; T/S: telomere-to-single copy gene; PCR: polymerase chain reaction; ANOVA: analysis of variance; CRP: C-reactive protein; n-6: omega-6; n-3: omega-3; EPA: eicosapentaenoic acid; DHA: docosahexaenoic acid; MD: Mediterranean diet.

\section{References}

[1] Blackburn EH, Epel ES and Lin J, Human telomere biology: A contributory and interactive factor in aging, disease risks, and protection. Science, 2015. 350(6265): p. 1193-8.

[2] Cassidy A, De Vivo I, Liu Y, Han J, Prescott J, Hunter DJ and Rimm EB, Associations between diet, lifestyle factors, and telomere length in women. Am J Clin Nutr, 2010. 91(5): p. 1273-80.

[3] Chen W, Kimura M, Kim S, Cao X, Srinivasan SR, Berenson GS, Kark JD and Aviv A, Longitudinal versus cross-sectional evaluations of leukocyte telomere length dynamics: agedependent telomere shortening is the rule. J Gerontol A Biol Sci Med Sci, 2011. 66(3): p. 312-9.

[4] Epel ES, Blackburn EH, Lin J, Dhabhar FS, Adler NE, Morrow JD and Cawthon RM, Accelerated telomere shortening in response to life stress. Proc Natl Acad Sci U S A, 2004. 101(49): p. 17312-5.

[5] Paul L, Diet, nutrition and telomere length. J Nutr Biochem, 2011. 22(10): p. 895-901.

[6] Kong CM, Lee XW and Wang X, Telomere shortening in human diseases. FEBS J, 2013. 280(14): p. 3180-93.

[7] Herrmann M, Pusceddu I, Marz W and Herrmann W, Telomere biology and age-related diseases. Clin Chem Lab Med, 2018.

[8] Block G, Jensen CD, Norkus EP, Dalvi TB, Wong LG, McManus JF and Hudes ML, Usage patterns, health, and nutritional status of long-term multiple dietary supplement users: a cross-sectional study. Nutr J, 2007. 6: p. 30.

[9] Xu Q, Parks CG, DeRoo LA, Cawthon RM, Sandler DP and Chen $\mathrm{H}$, Multivitamin use and telomere length in women. Am J Clin Nutr, 2009. 89(6): p. 1857-63.

[10] Lee JY, Shin C and Baik I, Longitudinal associations between micronutrient consumption and leukocyte telomere length. J Hum Nutr Diet, 2017. 30(2): p. 236-243. 
[11] Min KB and Min JY, Association between leukocyte telomere length and serum carotenoid in US adults. Eur J Nutr, 2017. 56(3): p. 1045-1052.

[12] Sen A, Marsche G, Freudenberger P, Schallert M, Toeglhofer AM, Nagl C, Schmidt R, Launer LJ and Schmidt $H$, Association between higher plasma lutein, zeaxanthin, and vitamin $\mathrm{C}$ concentrations and longer telomere length: results of the Austrian Stroke Prevention Study. J Am Geriatr Soc, 2014. 62(2): p. 222-9.

[13] Kiecolt-Glaser JK, Epel ES, Belury MA, Andridge R, Lin J, Glaser R, Malarkey WB, Hwang BS and Blackburn E, Omega-3 fatty acids, oxidative stress, and leukocyte telomere length: A randomized controlled trial. Brain Behav Immun, 2013. 28: p. 16-24.

[14] Richards JB, Valdes AM, Gardner JP, Paximadas D, Kimura M, Nessa A, Lu X, Surdulescu GL, Swaminathan R, Spector TD, and Aviv A, Higher serum vitamin D concentrations are associated with longer leukocyte telomere length in women. Am J Clin Nutr, 2007. 86(5): p. 1420-5.

[15] Farzaneh-Far R, Lin J, Epel ES, Harris WS, Blackburn EH and Whooley MA, Association of marine omega-3 fatty acid levels with telomeric aging in patients with coronary heart disease. JAMA, 2010. 303(3): p. 250-7.

[16] Abraham JE, Maranian MJ, Spiteri I, Russell R, Ingle S, Luccarini C, Earl HM, Pharoah PP, Dunning AM and Caldas C, Saliva samples are a viable alternative to blood samples as a source of DNA for high throughput genotyping. BMC Med Genomics, 2012. 5: p. 19.

[17] Cianga CM, Antohe I, Zlei M, Constantinescu D and Cianga P, Saliva leukocytes rather than saliva epithelial cells represent the main source of DNA. Revista Română de Medicină de Laborator, 2016. 24(1): p. 31-43.

[18] Puterman E, Gemmill A, Karasek D, Weir D, Adler NE, Prather AA and Epel ES, Lifespan adversity and later adulthood telomere length in the nationally representative US Health and Retirement Study. Proc Natl Acad Sci U S A, 2016. 113(42): p. E6335-E6342.

[19] Prasad KN, Wu M and Bondy SC, Telomere shortening during aging: Attenuation by antioxidants and antiinflammatory agents. Mech Ageing Dev, 2017. 164: p. 61-66.

[20] von Zglinicki T, Oxidative stress shortens telomeres. Trends Biochem Sci, 2002. 27(7): p. 339-44.

[21] Lonkar P and Dedon PC, Reactive species and DNA damage in chronic inflammation: reconciling chemical mechanisms and biological fates. Int J Cancer, 2011. 128(9): p. 1999-2009.

[22] Lee WP, Hou MC, Lan KH, Li CP, Chao Y, Lin HC and Lee $\mathrm{SD}$, Helicobacter pylori-induced chronic inflammation causes telomere shortening of gastric mucosa by promoting PARP-1mediated non-homologous end joining of DNA. Arch Biochem Biophys, 2016. 606: p. 90-8.

[23] Masi S, Salpea KD, Li K, Parkar M, Nibali L, Donos N, Patel K, Taddei S, Deanfield JE, D'Aiuto F, and Humphries SE, Oxidative stress, chronic inflammation, and telomere length in patients with periodontitis. Free Radic Biol Med, 2011. 50(6): p. $730-5$.

[24] Beilfuss J, Camargo CA, Jr. and Kamycheva E, Serum 25Hydroxyvitamin D Has a Modest Positive Association with Leukocyte Telomere Length in Middle-Aged US Adults. J
Nutr, 2017. 147(4): p. 514-520.

[25] Liu JJ, Prescott J, Giovannucci E, Hankinson SE, Rosner B, Han $J$ and De Vivo I, Plasma vitamin D biomarkers and leukocyte telomere length. Am J Epidemiol, 2013. 177(12): p. 1411-7.

[26] Shivappa N, Steck SE, Hurley TG, Hussey JR and Hebert JR, Designing and developing a literature-derived, populationbased dietary inflammatory index. Public Health Nutr, 2014. 17(8): p. 1689-96.

[27] Shivappa N, Wirth MD, Hurley TG and Hebert JR, Association between the dietary inflammatory index (DII) and telomere length and C-reactive protein from the National Health and Nutrition Examination Survey-1999-2002. Mol Nutr Food Res, 2017. 61(4).

[28] Paul L, Jacques PF, Aviv A, Vasan RS, D'Agostino RB, Levy $\mathrm{D}$ and Selhub J, High plasma folate is negatively associated with leukocyte telomere length in Framingham Offspring cohort. Eur J Nutr, 2015. 54(2): p. 235-41.

[29] Paul L, Cattaneo M, D'Angelo A, Sampietro F, Fermo I, Razzari C, Fontana G, Eugene N, Jacques PF and Selhub J, Telomere length in peripheral blood mononuclear cells is associated with folate status in men. J Nutr, 2009. 139(7): p. 1273-8.

[30] Rafie N, Golpour Hamedani S, Barak F, Safavi SM and Miraghajani M, Dietary patterns, food groups and telomere length: a systematic review of current studies. Eur J Clin Nutr, 2017. 71(2): p. 151-158.

[31] Crous-Bou M, Fung TT, Prescott J, Julin B, Du M, Sun Q, Rexrode KM, Hu FB and De Vivo I, Mediterranean diet and telomere length in Nurses' Health Study: population based cohort study. BMJ, 2014. 349: p. g6674.

[32] Medina-Remon A, Casas R, Tressserra-Rimbau A, Ros E, Martinez-Gonzalez MA, Fito M, Corella D, Salas-Salvado J, Lamuela-Raventos RM, Estruch R, and Investigators PS, Polyphenol intake from a Mediterranean diet decreases inflammatory biomarkers related to atherosclerosis: a substudy of the PREDIMED trial. Br J Clin Pharmacol, 2017. 83(1): p. 114-128.

[33] Tresserra-Rimbau A, Guasch-Ferre M, Salas-Salvado J, Toledo E, Corella D, Castaner O, Guo X, Gomez-Gracia E, Lapetra J, Aros F, Fiol M, Ros E, Serra-Majem L, Pinto X, Fito M, Babio N, Martinez-Gonzalez MA, Sorli JV, LopezSabater MC, Estruch R, Lamuela-Raventos RM, and investigators Ps, Intake of Total Polyphenols and Some Classes of Polyphenols Is Inversely Associated with Diabetes in Elderly People at High Cardiovascular Disease Risk. J Nutr, 2016.

[34] Tresserra-Rimbau A, Rimm EB, Medina-Remon A, MartinezGonzalez MA, Lopez-Sabater MC, Covas MI, Corella D, Salas-Salvado J, Gomez-Gracia E, Lapetra J, Aros F, Fiol M, Ros E, Serra-Majem L, Pinto X, Munoz MA, Gea A, RuizGutierrez V, Estruch R, Lamuela-Raventos RM, and Investigators PS, Polyphenol intake and mortality risk: a reanalysis of the PREDIMED trial. BMC Med, 2014. 12: p. 77.

[35] Leung CW, Fung TT, McEvoy CT, Lin J and Epel ES, Diet Quality Indices and Leukocyte Telomere Length among Healthy US Adults: Data from the National Health and Nutrition Examination Surveys (NHANES) 1999-2002. Am J Epidemiol, 2018. 